\title{
Poesia digital e ensino: o letramento literário em uma perspectiva tecnológica
}

\author{
Poesía digital y enseñanza: el letramento literario en una \\ perspectiva tecnológica
}

\section{Guilherme Moés Ribeiro de Sousa}

\author{
Universidade Estadual da Paraíba - UEPB - Campina Grande - Paraíba - Brasil
}

Flaviano Maciel Vieira

Universidade Federal da Paraíba - UFPB - João Pessoa - Paraíba - Brasil

\begin{abstract}
Resumo: Objetiva-se compreender a importância do letramento digital para a leitura de poesia produzida em suporte computacional e de como a escola, na condição de instituição de ensino, apresenta-se no processo de promoção desse letramento, o qual se mostra indispensável para a construção do letramento literário. Para tanto, foi implementada uma pesquisa bibliográfica em autores renomados nas áreas de Poesia Digital (ANTONIO, 2010; VIEIRA, 2017), de Letramento Digital (SANTAELLA, 2014; COSCARELLI; RIBEIRO, 2005; XAVIER, 2002) e de Letramento Literário (COSSON, 2014a, 2014b), com vistas a realizar uma discussão consistente acerca da temáticafoco deste estudo. Ainda, fez-se uma pesquisa em documentos parametrizadores da Educação Básica, a saber: Parâmetros Curriculares Nacionais, Orientações Curriculares para o Ensino Médio e a Base Nacional Comum Curricular, a fim de compreender como o ensino de linguagem sob uma perspectiva digital é contemplado nesses textos. Nesse sentido, evidenciou-se que, apesar de muitos avanços, a escola apresenta uma significativa dificuldade em promover o letramento digital dos alunos, o que dificulta o letramento literário dos discentes no que concerne à leitura de poesia digital. Como sugestão, apresenta-se, além de alguns sites, o aplicativo disponível para androide intitulado "PoemApps", o qual contém variados poemas digitais que podem facilitar o trabalho com a poesia digital em sala de aula, sendo utilizado como recurso tecnológico o celular/smartphone do próprio aluno.
\end{abstract}

Palavras-chave: Poesia digital. Ensino. Letramento Literário. Letramento digital.

Resumen: Se pretende comprender la importancia del letramento digital para la lectura de poesía producida en soporte computacional y de cómo la escuela, en la condición de institución de enseñanza, se presenta en el proceso de promoción de ese letramento, el cual se muestra indispensable para la construcción del letramento literario. Para ello, se implementó una investigación bibliográfica en autores renombrados en las áreas de Poesía Digital (ANTONIO, 2010; VIEIRA, 2017), de Letramento Digital (SANTAELLA, 2014, COSCARELLI, RIBEIRO, 2005; XAVIER, 2002) y de Letramento Literario (COSSON, 2014a, 2014b), con miras a realizar una discusión consistente sobre la temática focal de este estudio. También, se ha realizado una investigación en documentos parametrizadores de la Educación Básica, a saber: Parámetros Curriculares Nacionales, Orientaciones Curriculares para la Enseñanza Media y la Base Nacional Común Curricular, a fin de comprender cómo la enseñanza de lenguaje desde una perspectiva digital es contemplada en estos textos. En ese sentido, se evidenció que, a pesar de muchos avances, la escuela presenta una significativa dificultad en promover el letramento digital de los alumnos, lo que dificulta el letramento literario de los discentes en lo que concierne a la lectura de poesía digital. Como sugerencia, se presenta, además de algunos sitios, la aplicación disponible para androide titulado "PoemApps", el cual contiene variados poemas digitales que pueden facilitar el trabajo con la poesía digital en el aula, siendo utilizado como recurso tecnológico el celular/el smartphone del propio alumno.

Palabras-clave: Poesía digital. Enseñanza. Letramento Literario. Letramento digital. 


\section{Introdução}

Em pleno século $\mathrm{XXI}$, a cultura digital tem favorecido significativas transformações no âmbito da sociedade contemporânea. Em virtude do exponencial crescimento das tecnologias de comunicação e informação (TICs), percebe-se um quadro crescente de acesso a computadores, smartphones, tablets e outros aparelhos e recursos, e os estudantes, enquanto sujeitos inseridos no contexto social, encontram-se mergulhados nessa cultura digital. Não apenas enquanto meros consumidores, esses indivíduos têm se envolvido ativamente neste novo cenário social que se arranja de modo multimidiático e multimodal, promovendo a atuação dos jovens em redes de compartilhamentos de informações, possibilitando novas perspectivas de ver e agir sob o mundo (BRASIL, 2018).

\begin{abstract}
Todo esse quadro impõe à escola desafios ao cumprimento do seu papel em relação à formação das novas gerações. É importante que a instituição escolar preserve seu compromisso de estimular a reflexão e a análise aprofundada e contribua para 0 desenvolvimento, no estudante, de uma atitude crítica em relação ao conteúdo e à multiplicidade de ofertas midiáticas e digitais. Contudo, também é imprescindível que a escola compreenda e incorpore mais as novas linguagens e seus modos de funcionamento, desvendando possibilidades de comunicação (e também de manipulação), e que eduque para usos mais democráticos das tecnologias e para uma participação mais consciente na cultura digital. Ao aproveitar o potencial de comunicação do universo digital, a escola pode instituir novos modos de promover a aprendizagem, a interação e o compartilhamento de significados entre professores e estudantes. (BRASIL, 2018, p. 59)
\end{abstract}

Nesse sentido, a escolha do tema deste estudo foi feita com base em meu interesse pelo trabalho com a poesia, bem como pela incessante vontade de compreender as influências das tecnologias na educação, no ensino e na aprendizagem dos sujeitos. Nessa perspectiva, ao abordar a poesia digital no viés do ensino, é importante, de primeira instância, compreender algumas ideias. Dessa maneira, inicialmente, será desenvolvida uma discussão sobre o que seriam suportes textuais (MARCUSCHI, 2003), como eles evoluíram ao longo do tempo e quais são os impactos dessa evolução para os textos literários, em especial para o texto poético.

Feitas essas considerações, serão implementadas reflexões no tocante à importância dos multiletramentos (ROJO, 2012), com enfoque no letramento digital (COSCARELLI, 2016), diante das demandas da sociedade contemporânea, que se faz técnico-científica e informacional, e como esse(s) (multi)letramento(s) se faz(em) imprescindível(is) para o ensino da literatura em torno da poesia digital (JOBIM, 2005), especialmente no que se refere à leitura, isto é, ao letramento literário. Também será visto como esses aspectos estão contemplados nos documentos oficiais da Educação Básica, a saber: os Parâmetros Curriculares Nacionais (PCNs), as Orientações Curriculares para o Ensino Médio (OCEM) e a Base Nacional Comum Curricular (BNCC)

Diante desse panorama, será mostrada a indispensabilidade de se compreender a poesia digital como construção estética contemporânea permeada de discursos construídos por meio de diversas (inter)significações, a partir das quais a multimodalidade torna-se uma marca registrada. Outrossim, trata-se de um gênero híbrido que contempla aspectos relevantes dos novos paradigmas textuais, como, entre outros, a hipermidialidade, a interatividade, a não-linearidade e a hipertextualidade (VIEIRA, 2017).

Todavia, levar a poesia digital para o âmbito da sala de aula, fazendo com que os alunos tenham contato com esse tipo de formulação estética, é um desafio e tanto, visto que eles, comumente, já não possuem muito gosto pela literatura. Além disso, as condições estruturais e tecnológicas das instituições de ensino, embora tenham passado por reformulações positivas, ainda não possibilitam, seja pela falta de funcionamento adequado, seja pela falta de acesso ao alunado, um trabalho eficiente com recursos digitais (SILVA, 2016), apesar do fato de que os sujeitos que integram esse ambiente estejam rodeados, no cotidiano extraescolar, pelas tecnologias que permeiam a vida em sociedade. 
Partindo desse raciocínio, neste estudo pretende-se verificar os obstáculos e os possíveis caminhos para a inserção do trabalho com a poesia digital na sala de aula, com vistas a compreender a importância do letramento digital para a promoção do letramento literário. Para tanto, buscou-se entender quais os empecilhos tecnológicos encontrados no contexto escolar que obstruem o letramento digital; analisar quais habilidades e estratégias devem ser levantadas/implementadas para o trabalho com a leitura do texto poético (leia-se letramento literário) em suporte digital no âmbito da sala de aula e, nesse sentido, apresentar, como hipótese metodológica, o aplicativo disponível para androide intitulado "PoemApps", além de alguns sites, para servir de suporte para o trabalho com leitura de poesia digital em sala de aula; verificar como os documentos parametrizadores da Educação Básica tratam desses novos gêneros em contexto digital; e, por fim, averiguar a importância do letramento digital para a construção do letramento literário na leitura de poesia digital.

Dado o exposto, como mecanismo metodológico, empregar-se a pesquisa bibliográfica em autores-destaque na área de Poesia Digital (ANTONIO, 2010; VIEIRA, 2017), Letramento Digital (SANTAELLA, 2014; COSCARELLI \& RIBEIRO, 2005; XAVIER, 2002) e Letramento Literário (COSSON, 2014a, 2014b), com fins a construir um embasamento teórico consistente para a discussão que aqui é proposta. Será, nesse sentido, realizada uma análise sistêmica acerca dos principais empecilhos para o letramento digital dos alunos em contexto escolar, o que, consequentemente, irá influenciar no letramento literário no que concerne à leitura de Poesia Digital.

Passaremos, então, à abordagem teórica que alicerçou esta pesquisa, a partir da qual será articulada uma discussão em torno da intrínseca conexão existente entre o letramento digital e o letramento literário e qual a importância dessa relação para o desenvolvimento de intervenções pedagógicas cujo foco seja a leitura de poesia digital.

\section{A evolução dos suportes e as reconfigurações textuais}

Confunde-se constantemente 0 que seria gênero textual com 0 que seria suporte textual. Marcuschi (2003) deixa isso bem claro quando sugere a necessidade de um discernimento entre esses conceitos. Sendo assim, nesta seção, será implementada uma discussão em torno do que seria um suporte textual, passando por uma breve apresentação da sua evolução, das suas mudanças no decorrer do tempo, além de promover uma abordagem dos suportes dos textos literários, com ênfase no texto poético.

De primeira instância e de forma bem simplificada, o suporte de um gênero pode ser entendido como o espaço material que permite a materialização de um gênero textual, que passa a ser texto quando se encontra no suporte (MARCUSCHI, 2003). Em outras palavras, o suporte permite que um gênero de texto (uso da língua/linguagem) torne-se um texto (materialização do uso da língua/linguagem).

Essa noção inicial corrobora o pensamento de que o gênero que determina o suporte, o que é pertinente em alguns casos. Todavia, existem situações em que será o suporte quem irá determinar o gênero textual, pois, por exemplo, analogamente ao que exemplifica Marcuschi (2003), se tivéssemos o texto "Amora, estou com saudades de você! João." escrito em um pedaço de papel sobre a mesa de uma pessoa (de nome Amora) a quem foi destinado, constituir-se-ia o gênero bilhete. Caso o referido texto fosse exposto em um outdoor, seria uma declaração de amor a uma pessoa ou, até mesmo, uma propaganda da fruta conhecida por amora. Nesse caso, a depender do suporte no qual o escrito fosse posto, o gênero de texto mudaria. Nesse exemplo,

O certo é que o conteúdo não muda, mas o gênero é aqui identificado na relação com o suporte. Portanto, há que se considerar um caso de co-emergência, já que o gênero ocorre (surge, concretiza-se e circula) numa relação de fatores combinados no contexto emergente. (grifo do autor) (MARCUSCHI, 2003, p.10).

Diante dessa discussão e das definições insuficientes presentes no Dicionário Aurélio e no 
Houaiss, por exemplo, Marcuschi (2003, p.11) define suporte de um gênero como "um locus físico ou virtual com formato específico que serve de base ou ambiente de fixação do gênero materializado como texto." (grifo do autor). Nesse sentido, o autor considera três pontos fundamentais para 0 entendimento do que seja suporte de um gênero: I) o suporte é um lugar físico ou virtual; II) tem um formato específico; e III) serve para fixar e mostrar um texto.

Até o fax, a folha de papel era o principal suporte de textos, que fora, logo em seguida, substituída por telas de vidro. Dessa maneira, um dos grandes marcos da história dos suportes textuais é correspondente à invenção do computador. A partir disso, houve uma grande revolução no que faz menção às configurações dos textos, os quais passaram a se difundir no ciberespaço nas telas de smartphones, tablets, notebooks e leitores eletrônicos em geral (COSTA; SILVA; VILAÇA, 2013).

Em razão disso, Marcuschi (2003, p.9) esclarece que desde muito antes, os suportes de textos "variaram, indo das paredes interiores de cavernas à pedrinha, à tabuleta, ao pergaminho, ao papel, ao outdoor, para finalmente entrar no ambiente virtual da internet.". E, nesse sentido, Chartier (2002, p.8) complementa-o ao apontar que "As novas técnicas não apagam nem brutal nem totalmente os antigos usos, e a era do texto eletrônico será ainda, e certamente por muito tempo, uma era do manuscrito e do impresso.".

Em outras palavras, apesar de, muitas vezes, uma nova tecnologia parecer ofensiva e agressiva, a ponto de diluir as que a antecedem, sabe-se que as produções impressas ainda irão perdurar concomitante aos textos virtuais/digitais por muito tempo, haja vista a dependência da sociedade contemporânea no tocante ao texto palpável, escrito em folha de papel, e, ao mesmo tempo, a dificuldade em realizar leituras diante de telas luminosas e sem o contato afetivo que se costuma ter com 0 livro/material impresso e/ou manuscrito.

Dado o exposto, são bem evidentes as transformações pelas quais passaram os suportes de textos e, igualmente, as práticas de leitura e de escrita. Nesse contexto, torna-se interessante perceber o quanto a literatura também passa por esses processos históricos, ganhando destaque com a invenção da imprensa - até mesmo porque, nos primórdios, a literatura restringia-se à produção verbal oral, haja vista as grandes obras "líada" e "Odisseia", atribuídas a Homero (GOODY apud MORETTI, 2009).

No contexto deste milênio, a literatura ganha novos rumos, tanto no sentido de se difundir no mundo virtual, mantendo as estruturas originais, quanto reconfigurando-se enquanto uma nova produção estética (digital-born ${ }^{1}$ ), a qual contempla aspectos organizacionais hipermidiáticos, (inter)semióticos, interativos e multimodais, isto é, associações de signos e códigos que representam, de certa maneira, a realidade tecnológica e digital vivenciada pela sociedade. A exemplo, podemos citar os minicontos de ouvir (Figura 01) - isto mesmo, não são para ler, mas para escutar -, os quais permitem novas sensações ao leitor-ouvinte.

Figura 01: Minicontos de ouvir

\section{MINIC@NT OS DE @UVIR}

Projeto de literatura digital para pessoas com deficiência visual. Ou não.
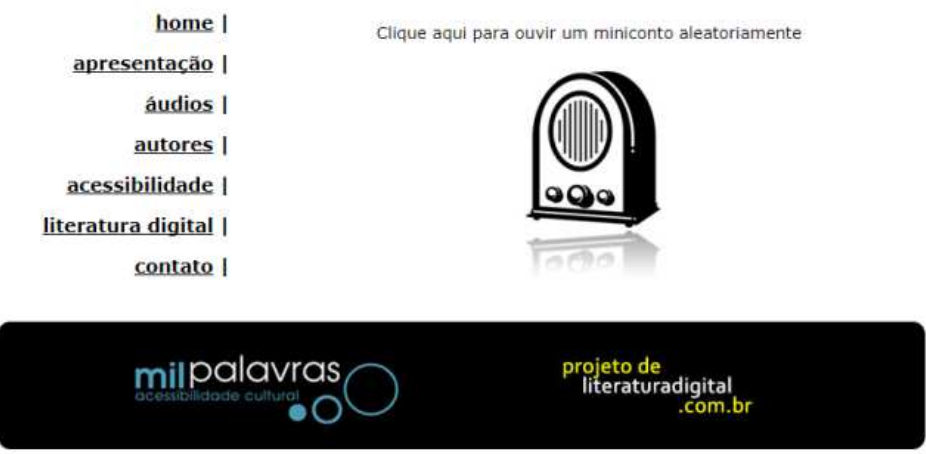

Fonte:http://www.literaturadigital.com.br/minicontosdeouvir/

Os minicontos coloridos surgem como uma maneira de permitir a interação do leitor, fazendo-o despertar para as associações semiótico-semânticas entre as cores e o texto. Por exemplo, como podemos verificar na Figura 04, o leitor é destinado a uma página da web na qual ele terá opções de escolher as

\footnotetext{
1 Refere-se às produções poéticas realizadas no próprio meio computacional (SANTAELLA, 2012 apud VIEIRA, 2017).
} 
porcentagens das cores, dentre as quais há entre as opções vermelho, verde e azul. Após isso, ao clicar em "Pinte seu Miniconto", o leitor é direcionado à página do miniconto, o qual terá relação com as escolhas percentuais das cores feitas, como se percebe na Figura 05, na qual se visualiza uma página completamente lilás (proveniente das misturas das cores azul e vermelho, selecionadas na Figura 02) associada a um picolé de uva apresentado no miniconto gerado.

Figura 02: Minicontos coloridos I minicontos coloridos

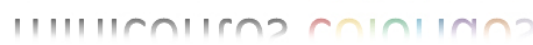

projeto experimental de literatura digital | edição e concepção de Marcelo Spalding | lançado em jan/2013

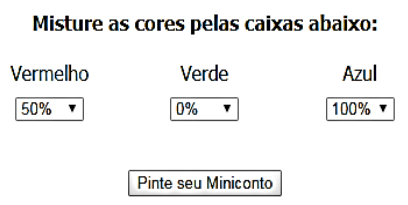

-- indicado para maiores de 14 anos --

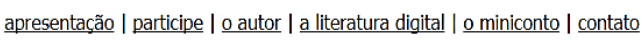

$$
\begin{aligned}
& \text { projeto de } \\
& \text { literaturadigital }
\end{aligned}
$$$$
\text { .com.br }
$$

Fonte: http://www.literaturadigital.com.br/minicontoscoloridos/

\section{Figura 03: Minicontos coloridos II}

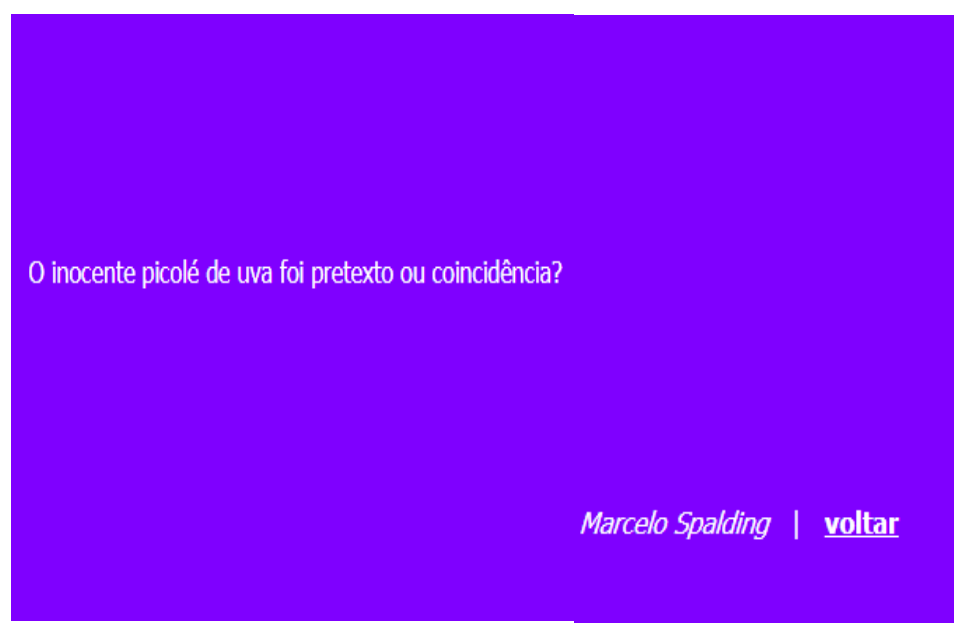

\section{Fonte:}

http://www.literaturadigital.com.br/minicontoscoloridos/miniconto.ph p? vermelho $=50$ \&verde $=0 \&$ azul $=100 \&$ button $=$ Pinte + seu + Miniconto

É interessante perceber, ainda, na Figura 03, o texto gerado "O inocente picolé de uva foi pretexto ou coincidência?", o que nos remete à possibilidade proveniente dessas formulações hipertextuais, as quais o leitor direciona sua própria leitura e atua como coautor da produção de linguagem. Nesse sentido, nada de coincidência, pois as porcentagens de cores definidas pelo lautor $^{2}$ é quem irão determinar o enredo do miniconto.

Além desses claros exemplos dos minicontos que expressam as novas (re)configurações literárias contemporâneas, não podemos deixar de tratar da poesia enquanto construção estética que hoje se apresenta completamente imbricada à tecnologia, passando a ser denominada de poesia digital, a qual será contemplada no capítulo a seguir.

\section{Os vieses da poesia digital: breves considerações}

Como já fora apresentado, a literatura e com ela os textos literários passaram por diversas transformações. Hoje, essas mudanças podem ser facilmente percebidas se observarmos as novas organizações estéticas presentes em contexto digital. Nesse panorama, a (re)configuração do texto poético em âmbito tecnológico - a poesia digital - ganha destaque pelas suas diversas características, as quais são apresentadas adiante.

3.1 O texto poético em contexto tecnológico: o que é poesia digital

A poesia digital compreende uma (re)significação do texto poético, o qual, em um primeiro momento é canônico, manuscrito e/ou impresso, e que, agora, passa a ganhar o ciberespaço, sendo caracterizado pela linguagem da hipermídia (MUNARI, 2011). Na verdade, o texto poético digital é uma construção de linguagem recheada de recursos que permitem uma maior interatividade entre leitor e texto, a partir de elementos estéticos inovadores do ponto de vista

\footnotetext{
${ }^{2}$ Termo cunhado por Rojo (2013) para se referir ao leitor da web 2.0, o qual, além de leitor propriamente dito, atua como (co)autor do texto.
} 
tecnológico, compreendendo desde uma abordagem das cores, como do movimento das letras, das palavras e/ou do texto como um todo, além da estruturação hipertextual, dentre outros aspectos.

Ao "saltar" da folha à tela do computador, a poesia passa a ser tida como

Essa nova configuração da palavra, essa nova forma de "escrever" com a palavra (...), onde se processam bits em forma de feixes de luz, que bailam no espaço da tela numa linguagem binária e ao sabor dos softwares (programas de computador) (...) (grifos do autor) (VIEIRA, 2017, p.15)

É justamente essa "nova forma de 'escrever"” que Vieira (2017) aponta que configura a linguagem implementada na formulação da poesia no computador na condição de digital-born. Nesse sentido, essa hipermidialidade marcante da poesia digital também é profundamente marcada por elementos caracterizadores da hipertextualidade, os quais pressupõem, inclusive, a não-linearidade (ANTONIO, 2010). Isso porque os hipertextos caracterizam-se por possibilitar ao leitor a escolha de quais direcionamentos ele dará à leitura - daí o caráter não-linear -, obviamente respeitando seus limites de coerência. É a partir dessa linha de raciocínio que Santaella (2014, p.55) esclarece que "O hipertexto não é feito para ser lido do começo ao fim, mas sim através de buscas, descobertas e escolhas".

Para exemplificar, de forma bem simples, a hipertextualidade marcante da poesia digital, vejamos a Figura 04 a seguir.

Figura 04: Exemplo da hipertextualidade em poesia digital I
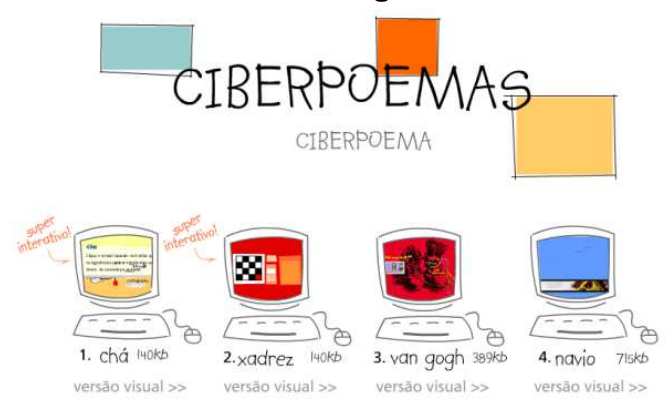

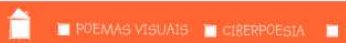

Fonte: http://www.ciberpoesia.com.br/
Essa figura corresponde à página da web de um site de ciberpoemas. Nela, podemos verificar, logo de início, a possibilidade do leitor escolher um dentre dez poemas disponíveis. Assim, ao clicar sob, por exemplo, o poema de número 1, "chá", o leitor é redirecionado a uma tela em que ele será esclarecido de como deverá se dar sua a interação com o texto (Figura 05) e, desta maneira, ele poderá interagir com os recursos do ciberespaço, de forma a, com o cursor do mouse, adicionar à xícara os ingredientes necessários ao preparo de um chá (Figura 06). Todavia, além dos ingredientes tradicionais, como água e a essência, há uma fotografia, estrelas e corações. Após a mistura dos ingredientes, içam da xícara versos em movimentos que, juntos, dão origem a um poema (Figura 07).

Figura 05: Exemplo da hipertextualidade em poesia digital II

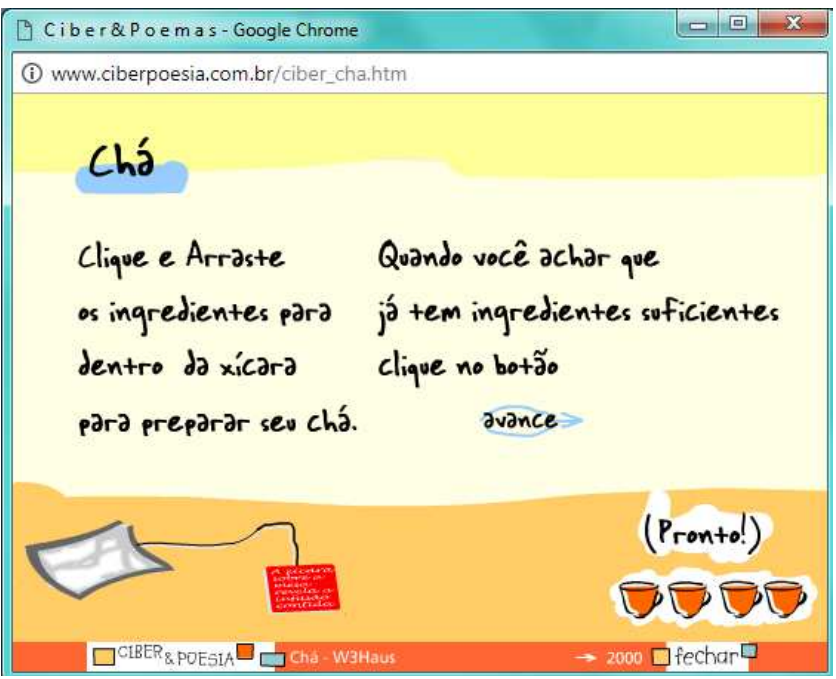

Fonte: http://www.ciberpoesia.com.br/ciber_cha.htm 
Figura 06: Exemplo da hipertextualidade em poesia digital III

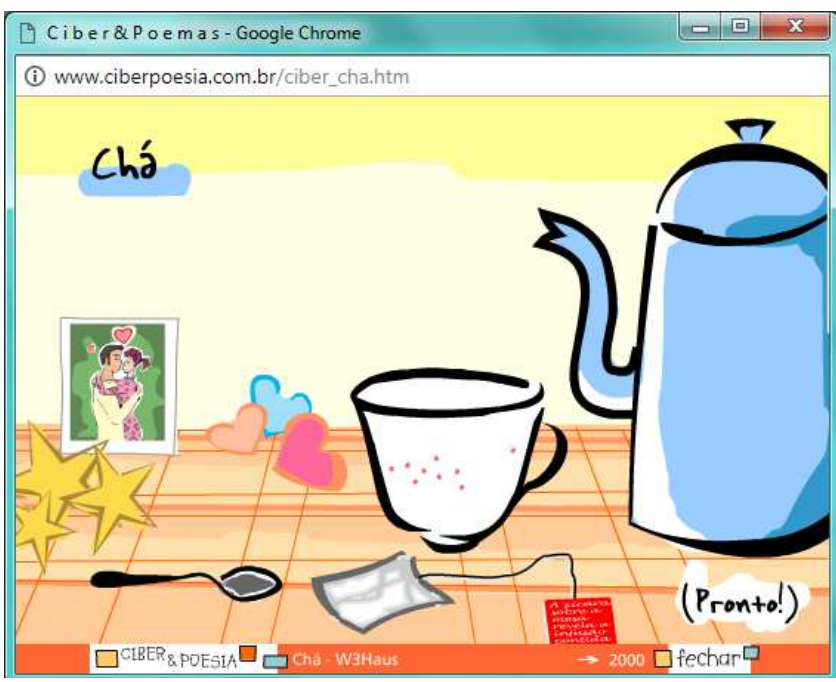

Fonte: http://www.ciberpoesia.com.br/ciber_cha.htm

Figura 07: Exemplo da hipertextualidade em poesia digital IV

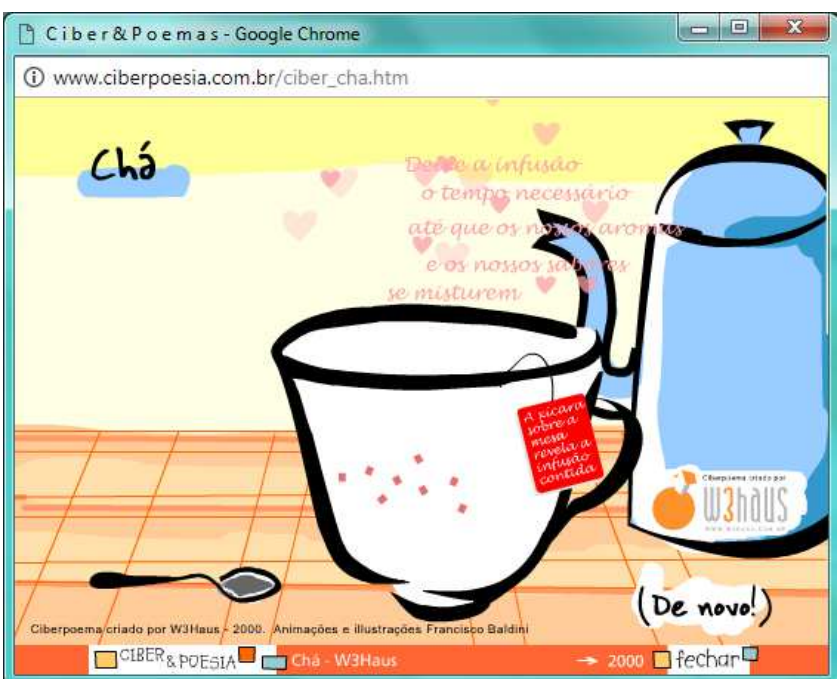

Fonte: http://www.ciberpoesia.com.br/ciber_cha.htm

No poema digital "chá", a formulação final que emerge da xícara verso por verso, tem-se a mensagem "Deixe a infusão/ o tempo necessário/ até que os nossos aromas/ e os nossos sabores/ se misturem", o que é algo inteiramente correlacionado à própria produção poética digital e que preconiza o uso da metalinguagem. A partir desse exemplo, podemos ter uma noção de como a hipertextualidade é construída, em que o clique em um link leva o lautor a outra página/situação comunicativa, sendo que a escolha é feita por parte dele, o que pressupõe uma não-linearidade e que isso é feito de forma totalmente interativa, haja vista que o leitor participa como coautor do texto.

Além disso, verifica-se o quanto é marcante a presença de aspectos multimodais no texto poético computacional, haja vista a diversidade de cores, os efeitos sonoros, a movimentação de imagens e de textos, dentre outros. Inclusive, em decorrência dessa variedade de composições das poesias digitais, Vieira (2017) vai apresentar seis categorias poético-digitais (verbo-digital, HHMI, tradução-inter-códigos, sonoropoético-digital, tempo-poético-digital e imagéticodigital), com vistas a traçar estratégias de leituras para poemas digitais que abarquem as características de pertencimento a cada categoria.

\section{Os documentos parametrizadores, 0 letramento digital e o ensino de linguagens}

Acerca do ensino da literatura veiculada e produzida em contexto computacional, há orientações que são apresentadas em importantes diretrizes do ensino de língua(gens) e de literatura para a Educação Básica no Brasil. Como exemplos, podemos mencionar os Parâmetros Curriculares Nacionais (PCNs), as Orientações Curriculares para o Ensino Médio (OCEM) e, recentemente lançada, temos a Base Nacional Comum Curricular (BNCC).

\subsection{Os Parâmetros Curriculares Nacionais}

De primeira instância, trataremos dos PCNs de Língua Portuguesa. Eles compreendem aspectos gerais a serem tomados como base para o ensino da língua materna nas quatro primeiras séries do Ensino Fundamental, o que corresponde ao Ensino Fundamental I ou Segundo Ciclo do Ensino Fundamental (PCNs, 1997). Nesse documento, é importante destacar dois dos seus objetivos, a saber:

- utilizar as diferentes linguagens - verbal, matemática, gráfica, plástica e corporal como meio para produzir, expressar e comunicar suas idéias, interpretar e usufruir das produções culturais, em contextos públicos e privados, atendendo a diferentes intenções e situações de comunicação; 
- saber utilizar diferentes fontes de informação e recursos tecnológicos para adquirir e construir conhecimentos; (grifos nossos) (PCNs, 1997, p.9).

Como se podem verificar, evidentemente, os Parâmetros destacam a importância de se saber/utilizar as diferentes linguagens e, em seguida, traz a relevância do uso de recursos tecnológicos. Nessa perspectiva, apesar de não ser pontuada especificamente a linguagem hipermidiática (MUNARI, 2011), eles enfatizam a necessidade do uso das diferentes linguagens com vistas a atender a demanda das produções culturais. Sendo assim, a produção de Poesia Digital, enquanto construção e representação de cultura humana em tempos contemporâneos, representando diversos aspectos do pensamento humano - hipertextual, acelerado, não-linear -, apresenta-se como fundamental para ser transposta didaticamente.

\subsection{As Orientações Curriculares para o Ensino Médio}

Quando tratamos do Ensino Médio, convém referenciarmos as OCEM. Nelas, a ideia do letramento digital e da linguagem tecnológica estão fortemente marcadas, embora se destaque, também, que os desafios para a implementação dos usos tecnológicos em sala de aula sejam uma realidade indiscutível:

Entendemos que a proposta de inclusão
digital remete à necessidade da
"alfabetização" dessa nova linguagem
tecnológica e de suprimentos, como
computadores e banda larga para a
navegação na Internet. Requer, pois,
preparação. (BRASIL, 2006, p.95)

Além disso, ao mencionar os termos "letramento" e a modalidade digital da leitura, esse documento sugere um projeto de letramento que alicerce a inclusão digital, o que é muito importante, conquanto saibamos das divergências que há entre o que está no papel e o que compreende a realidade dos sujeitos no âmbito escolar.

O projeto de letramento pode coadunar-se com a proposta de inclusão digital e social e atender a um propósito educacional, pois possibilita o desenvolvimento do senso de cidadania. (...) No que concerne à leitura, contempla pedagogicamente suas várias modalidades: a visual (mídia, cinema), a informática (digital), a multicultural e a crítica (presente em todas as modalidades). (BRASIL, 2006, p.98)

Logo, o papel do professor diante do ensinoaprendizagem de leitura digital - enfaticamente - é, justamente, mediar a passagem dos saberes com os quais boa parte dos discentes tiveram contato no contexto extraescolar, isto é, o docente deve buscar fortalecer significativamente o letramento digital dos sujeitos, abordando os aspectos do "(...) corpo humano virtualizado, digitalizado pelas diversas mídias contemporâneas: televisão, vídeo, cinema, computador." (2006, p.198).

\subsection{A Base Nacional Comum Curricular}

\section{A Base Nacional Comum Curricular (BNCC)} para o Ensino Fundamental apresenta uma ideia fundamental, em se tratando da área de Linguagens, a qual aponta para um viés que visa tornar nítido “(...) que as linguagens são dinâmicas, e que todos participam desse processo de constante transformação." (BRASIL, 2018, p.61). Nesse sentido, a BNCC apresenta cinco competências a serem alcançadas pelos discentes do Ensino Fundamental, dentre as quais vale destacar a seguinte:

5. Compreender e utilizar tecnologias digitais de informação e comunicação de forma crítica, significativa, reflexiva e ética nas diversas práticas sociais (incluindo as escolares), para se comunicar por meio das diferentes linguagens e mídias, produzir conhecimentos, resolver problemas e desenvolver projetos autorais e coletivos. (BRASIL, 2018, p.62)

Certamente, como se pode observar, a influência tecnológica na sociedade contemporânea é tanta que se tornou, até certo ponto, inviável falar de educação sem falar de tecnologia. Especialmente quando nos debruçamos sobre a área de linguagens, isso é notável na imensidão de gêneros alocados em suportes digitais e no consequente consumo da cultura digital que se vive no presente. Sendo assim, a poesia digital enquanto expressão estética cujo 
alicerce é o ciberespaço, a linguagem hipermidiática é facilmente contemplada nos preceitos que regem a BNCC

\section{A poesia digital na escola: desafios e possibilidades}

O espaço concedido à poesia em sala de aula é ainda menor do quê o que é concedido à literatura enquanto disciplina na Educação Básica. Se a arte literária que passou a ser escolarizada já é vista e tratada com certo estigma pela própria instituição escolar, haja vista a quantidade reduzida de aulas, uma abordagem simplista com uso do texto literário como pretexto para o ensino de gramática, dentre outros aspectos, à poesia resta um lugar ínfimo. A poesia a que nos referimos aqui é aquela com a qual os alunos costumam se deparar nos livros didáticos, a qual, na verdade, fica restrita a pequenos fragmentos de textos maiores; refiro-me à poesia do cânone literário, à poesia com rima, musicalidade, ritmo, métrica, estritamente escrita no papel, estática.

Por sua vez, quando se trata da poesia digital em si, a palavra de ordem é omissão. Na verdade, é praticamente inexistente - para não se dizer nula - a existência de práticas de sala de aula em que a poesia digital apareça como objeto de ensinoaprendizagem. Esse cenário deve ser repensado à medida que se tem a poesia digital enquanto um gênero textual emergente (ARANHA; BORBOREMA, 2016) e que demanda do aprendente habilidades e competências (BRASIL, 2018) próprias da sociedade contemporânea, que se faz técnico-científica, informacional e tecnológica.

Tendo em vista isso, compreender o papel da escola enquanto agência de construção de (multi)letramentos - mais especificamente do letramento digital como alicerce para o literário, haja vista as (re)construções estéticas em contexto computacional - faz-se indispensável diante da sociedade global deste milênio, e é justamente isso que se pretende discutir neste capítulo.

Para iniciarmos a discussão sobre letramento, faz-se preciso distingui-lo de alfabetização. Sendo assim, a alfabetização, conforme os pressupostos de Kleiman (2007), estaria relacionada à aquisição dos códigos da língua, de tal forma que o seu uso esteja restrito à circunstância de mera decodificação, sem uma consciência efetiva e prática das suas possibilidades de uso. Por sua vez, o letramento seria uma prática social de língua(gem), isto é, refere-se à utilização, por parte do sujeito, dos códigos de uma língua de forma consciente, compreendendo as especificidades de uso a depender das situações comunicativas.

Sabendo disso, compreender a instituição escolar enquanto espaço para promoção de (multi)letramentos (ROJO, 2012), é conceder a ela a função de instauradora da inclusão social. Até mesmo porque vivemos em uma sociedade letrada, a qual exige dos seus integrantes conhecimentos suficientes para que eles possam estabelecer comunicação entre si em circunstâncias as mais variadas, ou seja, demanda dos indivíduos maneiras de agir diferenciadas a depender a situação.

$\mathrm{Na}$ sua obra, Círculos de Leitura e Letramento Literário, Cosson (2014b) chega a fazer menção à literatura digital e à relevância de se letrar os alunos nesse sentido, todavia essa discussão é resumida em poucos parágrafos de sua obra. Apesar da compactação, no sentido lato da palavra, da literatura digital na obra de Cosson (2014b), ele aponta para um aspecto especial dessa produção estética quando diz que:

Nessa nova literatura, as marcas mais evidentes são o fragmento ou a fragmentação tal como possibilitada pelo hipertexto; a interação, que aproxima o texto literário do jogo e da criação conjunta, apagando ou tornando menos nítidas as posições de leitor e autor; a construção textual em camadas superpostas e multimodais, como resultado da exploração dos muitos recursos disponibilizados pelo meio digital. (COSSON, 2014b, p. 18)

Nessa perspectiva, a literatura, melhor dizendo, o letramento literário digital deve ser um dos focos da escola. Isso porque, conforme sugere Candido (2004), a literatura deve ser encarada como um direito humano, sendo um bem incompressível, isto é, indispensável à sobrevivência humana, assim como o direito à alimentação, à moradia, dentre 
outros que se fazem imprescindíveis à integridade física do sujeito. Inclusive, segundo ele, a literatura vai além por permitir e garantir a integridade espiritual do homem.

Ainda, de acordo com o autor, a literatura tem um caráter humanizador muito importante à medida que, por meio da sua produção, permite 0 desenvolvimento da sensibilidade do ser diante de causas como o racismo, o preconceito, a discriminação das classes menos favorecidas, dentre outras. Em especial, no contexto educacional, a literatura funciona como uma ferramenta poderosa com vistas ao desenvolvimento intelectual/cognitivo e afetivo dos sujeitos.

Não obstante, o problema que se tem hoje ao acesso à literatura por parte da massa populacional, em especial aos alunos, é algo ainda grave, mesmo diante das ações ativistas que pleiteiam o acesso aos bens materiais e morais que garantem a dignidade do indivíduo. E é justamente por apresentar uma relação tão intrínseca com os Direitos Humanos, que a literatura é uma questão de cidadania, pois ela possibilita às pessoas o agir crítico, reflexivo e participativo diante da sociedade na qual estão inseridas, favorecendo o exercício do papel do cidadão (CANDIDO, 2004). Nessa linha de raciocínio, complementando a ideia de Candido (2004), as OCEM (2006, p.54) apontam para a necessidade de "formar o leitor literário, melhor ainda, de 'letrar' literariamente o aluno, fazendo-o apropriar-se daquilo a que tem direito.".

Assim, a poesia digital, enquanto literatura contemporânea, também se faz direito humano incompressível e, por isso, o acesso a ela por parte dos alunos é de extrema importância. Todavia, para usufruir dessa construção estética, a escola tem, sob a ótica da literatura como direito humano, violado um direito básico do cidadão, à medida que não favorece o trabalho com a poesia digital, haja vista que não favorece o letramento digital tão essencial para uma prática efetiva de letramento com essa construção estética poética computacional.

As dificuldades que perpassam o contexto scolar nesse sentido vão desde a falta de materiais tecnológicos, como computadores e laboratório de informática, de acesso à internet, principalmente em instituições periféricas às cidades, à existência de materiais de alta qualidade. Na maioria das vezes, nesse último caso, os alunos não têm acesso a esses recursos por questões meramente burocráticas, melhor dizendo ignorantes, por parte de coordenações/direções escolares, as quais veem, muitas vezes, o aluno como um ser destruidor que irá acabar com todos os instrumentos que foram adquiridos a altos valores ${ }^{3}$.

Sendo assim, uma estratégia pertinente a ser adotada pelos professores é a utilização, em sala de aula, dos próprios aparelhos celulares/smartphones dos alunos, a fim de que seja realizado um trabalho, ao menos paliativo, com a tecnologia em sala de aula, explorando a poesia digital em aplicativos disponíveis no Play Store, como o "PoemApps" (Figura 08), o qual disponibiliza poesia interativa para celulares. Nele, podemos encontrar vários poemas digitais de autoria de Gab Marcondes e Bruno Viana, como o intitulado "Saudades", conforme Figura 09.

\section{Figura 08: Aplicativo "PoemApps"}

\begin{tabular}{|c|c|}
\hline Actc & Doublets \\
\hline alli & Poema Pela Cidade \\
\hline 9 & Poema RGB \\
\hline$\phi$ & Oriente \\
\hline (4) & Poema Fatorial \\
\hline$\theta$ & Poema em 12 tempos \\
\hline$\Rightarrow$ & Sopro \\
\hline 8 & Ampulheta \\
\hline$m$ & Saudades \\
\hline$\downarrow$ & Pêndulo \\
\hline$n$ & Significante \\
\hline
\end{tabular}

Fonte: PoemApps, Play Store.

\footnotetext{
${ }^{3}$ Essa ideia é bem representada na produção cinematográfica "Escritores da liberdade", em que a professora recém-chegada na instituição de ensino quer abrir a biblioteca aos seus alunos, a fim de que eles possam ler e levar os livros para casa emprestados, todavia as instâncias superiores da escola criam resistência com a justificativa de que os discentes iriam destruir aquilo que foi tão custoso.
} 
Figura 09: Poema "Saudades"

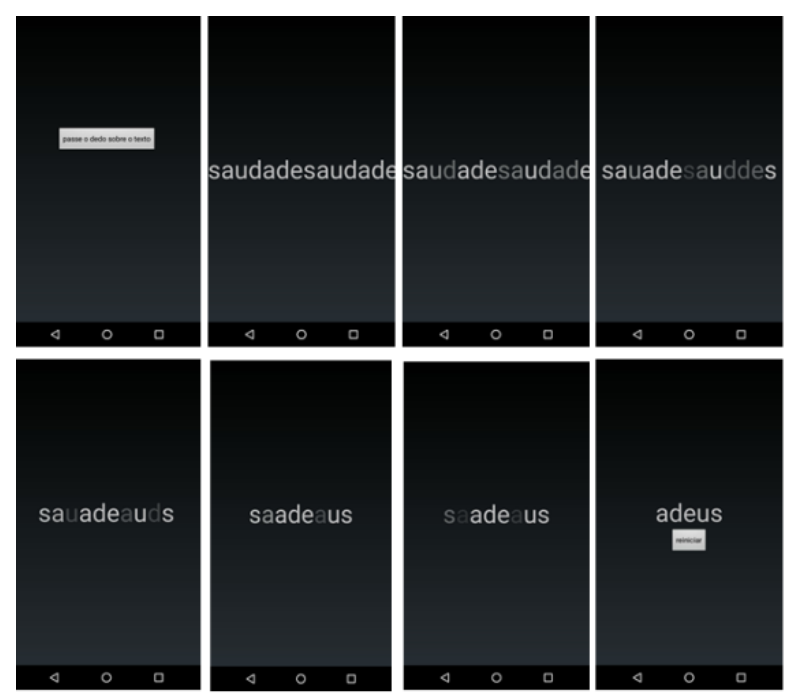

Fonte: PoemApps, Play Store.

$\mathrm{Na}$ Figura 09, verifica-se marcantemente a interatividade e a multimodalidade como elementoschave na construção de sentido(s) do poema "Saudades". Nesse sentido, é interessante perceber, em uma leitura bem superficial, como a saudade é construída a partir do apagamento material de algo, que "vai embora", isto é, dá um "adeus". Essa sensação é articulada a partir da transparência que as letras vão ganhando à medida que se clica na tela do dispositivo móvel.

Dessa forma, esse aplicativo mostra-se muito chamativo para a realização do trabalho com poesia digital em sala de aula, até mesmo porque, em decorrência da disseminação tecnológica, grande parte dos alunos costumam ter dispositivos celulares, o que possibilita o desenvolvimento de atividade com o "PoemApps". Além do próprio aplicativo, sites como ciberpoesia.com.br, pauloaquarone.com, nomuque.net (Artéria 8), podem se mostrar grandes aliados do professor, o qual poderá realizar suas aulas evocando as práticas de letramento digital já pertencentes aos alunos, haja vista a facilidade que eles têm em manusear o aparelho celular e os aplicativos/softwares de um modo geral, e, desta forma, promover o letramento literário no tocante à leitura de poesia digital.

Em sala de aula, o docente pode lançar, por exemplo, a estratégia de formar um círculo com os alunos e, cada qual, escolher uma poesia digital que chame sua atenção. Nesse sentido, cada aluno iria, um a um, ao centro do círculo para expor à turma a poesia que escolhera, esclarecendo as significações que dela podem ser inferidas. Desta maneira, os discentes teriam a possibilidade de verificar na prática como se dá a interatividade da poesia digital e socializar suas visões a respeito disso com os seus colegas.

Atividades como essa favorecem, em muito, o trabalho do professor no que concerne à leitura e interpretação de textual, tendo em vista os sistemas de códigos diferenciados abrigados na poesia digital. $\mathrm{E}$, certamente, não há nada que seja tão plurissignificativo como a poesia, e quanto à digital $e$ a sua interatividade (ARANHA; BORBOREMA, 2016) dispensa comentários.

Fazendo um trabalho sistemático em torno da poesia digital, o docente estará vinculando às suas práticas as prerrogativas apresentadas nos documentos parametrizadores, especialmente em se tratando da significância do letramento digital e sua relação com o literário. Essa perspectiva é um dos se não o - principais alicerces para o enfrentamento dos desafios curriculares, os quais, muitas vezes, obstruem o fortalecimento da aprendizagem.

\section{Considerações finais}

Por todas as questões discutidas no decorrer deste trabalho, verificou-se como a leitura e a escrita, e com elas os textos, evoluíram com o tempo, o que provocou o surgimento de novos suportes para os gêneros textuais, que são os suportes digitais. É exatamente neste ponto em que a poesia digital entra em cena enquanto produção textual literária de caráter estético computacional e que demanda dos sujeitos-leitores habilidades e competências que outrora não eram exigidas.

Comprovou-se, inclusive, que embora vivamos em uma sociedade que preconiza o uso de recursos tecnológicos em sala de aula, chegando a tornar indissociável a educação e o estudo de linguagens da tecnologia, ainda há muito o que se fazer para que, de fato, os estudantes tenham o acesso ao 
letramento digital-literário tão essencial a sua formação enquanto cidadão e ser humano repleto de direitos que lhes são negados.

Percebe-se que a escola deixa a desejar ao tentar cumprir sua função e, em se tratando da poesia digital, o problema é pior, pois, muitas vezes, os recursos tecnológicos estão lá, mas são de uso restrito - para não dizer impossível. Resta ao professor desenvolver estratégias e compreender a realidade do aluno com vistas a utilizar em sala de aula os recursos que os discentes trazem consigo, como os seus celulares, por exemplo.

Em linhas gerais, verifica-se que, apesar dos obstáculos enfrentados pela escola na promoção do letramento digital e do literário, o trabalho com a poesia digital é possível, principalmente quando se considera a realidade dos sujeitos, os quais são nativos digitais, e se utiliza de um recurso amplamente utilizado pelos discentes, de forma a permitir o desenvolvimento do letramento literário sob uma perspectiva tecnológica a partir da leitura de poesia digital por meio do aplicativo "PoemApps".

\section{Referências}

ANTONIO, Jorge Luiz. Poesia digital: negociações com os processos digitais: teoria, história, antologias. São Paulo: Navegar Editora, 2010.

ARANHA, Simone Dália de Gusmão; BORBOREMA, Olivia Rodrigues. A interatividade na poesia digital: palavra, imagem e som em movimento. Belo Horizonte: Texto Livre: Linguagem e Tecnologia, v. 9 , n. 2, p. 46-63, jul.-dez. 2016.

BRASIL. Base Nacional Comum Curricular. Ensino Fundamental. Brasília: Ministério da Educação, Secretaria de Educação Básica, 2018.

BRASIL. Orientações Curriculares para o Ensino Médio - Volume 1 - Linguagens, códigos e suas tecnologias. Brasília: Ministério da Educação, Secretaria de Educação Básica, 2006. 239 p.

BRASIL. Parâmetros curriculares nacionais: língua portuguesa. Brasília: Ministério da Educação, Secretaria de Educação Fundamental, 1997, $144 p$.

CANDIDO, Antonio. O direito à literatura. In: . Vários escritos. 4ª ed. São Paulo/Rio de Janeiro: Duas Cidades/Ouro sobre Azul, 2004, p. 169-191.
CHARTIER, Roger. Os desafios da escrita. São Paulo: Unesp, 2002.

COSCARELLI, Carla Viana. Tecnologias para aprender. 1. ed. - São Paulo: Parábola Editorial, 2016.

COSCARELLI, Carla Viana; RIBEIRO, Ana Elisa. (Orgs.). Letramento digital: aspectos sociais e possibilidades pedagógicas. Belo Horizonte: Autêntica, 2005.

COSSON, Rildo. Letramento literário: teoria e prática. 2. ed., 5a reimpressão. - São Paulo: Contexto, $2014 a$.

COSSON, Rildo. Círculos de leitura e letramento literário. São Paulo: Contexto, 2014b.

COSTA, R. C; SILVA, R.; VILAÇA, M. L. C. A evolução e revolução da escrita: um estudo comparativo. XVII Congresso Nacional de Linguística e Filologia, 2013.

GOODY, Jack. Da oralidade à escrita: Reflexões antropológicas sobre 0 ato de narrar. In: MORETTI, Franco (org.). O Romance 1: A cultura do romance. Tradução Denise Bottmann. São Paulo: Cosac Naify, 2009.

JOBIM, José Luís. Literatura e informática/José Luís Jobim (org.). - Rio de Janeiro: EdUERJ, 2005.

KLEIMAN, A. Letramento e suas implicações para o ensino de língua materna. In: Signo. Santa Cruz do Sul, v. 32 n 53, p. 1-25, dez, 2007. Disponível em:

http://online.unisc.br/seer/index.php/signo/article/vi ewFile/242/196. Acesso em: 22 de outubro de 2017.

MARCUSCHI, L. A. A questão do suporte dos gêneros textuais. Revista DLCV - Língua, linguística e literatura, João Pessoa, v. 1, n.1, p. 940, 2003.

MUNARI, Ana Cláudia. Literatura e internet. Anais da XI Semana de Letras da Pontifícia Universidade Católica do Rio Grande do Sul (PUC-RS), Porto Alegre/RS, 2011. Disponível em: http://ebooks.pucrs.br/edipucrs/anais/XISemanaDe Letras/pdf/anamunari.pdf. Acesso em: 30 de novembro de 2017.

ROJO, Roxane Helena Rodrigues. Multiletramentos na escola. São Paulo: Parábola Editorial, 2012.

ROJO, Roxane Helena Rodrigues (org.). Escola Conectada: os multiletramentos e as TICS. São Paulo: Parábola Editorial, 2013.

SANTAELLA, Lucia. O novo estatuto do texto nos ambientes de hipermídia. IN: SIGNORI, Inês [org.]. [Re]discutir texto, gênero e discurso. 1. ed. São Paulo: Parábola Editorial, 2014. 
SILVA, Maria Valdênia da. O texto literário e suas múltiplas linguagens. In: PEREIRA, Jaqueânia Aristides; SILVA, Maria Valdênia da (Orgs.). Literatura e outras linguagens. Coleção Crítica e Ensino 8.- Campina Grande: Bagagem, 2016.

VIEIRA, Flaviano Maciel. Como ler poéticas digitais: perspectivas de leituras. Tese de Doutorado. João Pessoa, 2017.

XAVIER, A. C. dos S. Letramento digital e ensino. 2002. Núcleo de Estudos de Hipertexto e Tecnologia Educacional - NEHTE. Disponível em: https://escolafutura.files.wordpress.com/2013/11/le tramento-digital-e-ensino.pdf. Acesso em 22 de outubro de 2017.

\section{COMO CITAR ESSE ARTIGO}

SOUSA, Guilherme Moés Ribeiro de; VIEIRA, Flaviano Maciel. Poesia digital e ensino: o letramento literário em uma perspectiva tecnológica. Signo, Santa Cruz do Sul, v. 43, n. 78, nov. 2018. ISSN 1982-2014. Disponível em: <https://online.unisc.br/seer/index.php/signo/article/view/11991>. Acesso em: doi: ttps://doi.org/10.17058/signo.v43i78.11991. 